\title{
History of autism. The beginnings. Collusions or serendipity
}

\section{Loredana AL GHAZI•}

\begin{abstract}
The article presents the first years of the autism and the way it was viewed since the autistic features were first observed until 75 years ago when Leo Kanner coined the term "autism". It took 36 years to Kanner's "infantile autism" to be formally recognized by the American Psychiatric Association in the third edition of the Diagnostic and Statistical Manual (APA, 1980). Fifty years after Hans Asperger published his four cases of "autistic psychopaths", whose traits were described as early as 1938 in his postdoctoral thesis, APA introduced the Asperger syndrome in the fourth edition of DSM(1994). However, two decades before Kanner and Asperger, a Russian psychiatrist, Grunia Sukhareva, reported six cases of "schizoid psychopathy" in children and used the term autistic to describe their "tendency towards solitude and avoidance of other people" (Wolff, 1996, p. 129). We bring together three recent extensive accounts on autism history and try to establish who was the first to observe, describe, and label the autistic traits as a separate clinical picture from childhood schizophrenia.
\end{abstract}

Keywords: infantile autism; Asperger syndrome; schizoid psychopathy.

"Nothing is totally original. Everyone is influenced by what's gone before."

Lorna Wing (1981) the architect of the spectrum model of autism and mother of a girl with ASD

\section{Introduction}

For decades, when presenting the history of autism, authors usually start by quoting Leo Kanner's landmark articles on autistic disturbances (Kanner, 1943) and early infantile autism (Kanner, 1944), also known as Kanner syndrome. Immediately after, Kanner is cited in Hans Asperger's work, and Lorna Wing (1981) name it as Asperger Syndrome. Instead of going directly to those two great pioneers' papers or delve into the vast databases of scientific literature, we propose to take a trip to the past and travel around with some

- Lecturer, PhD, Department of Educational Sciences, The University Clinic for Therapies and PsychoPedagogical Counselling, West University of Timișoara, loredana.al@e-uvt.ro 
special guides, nor psychiatrists or psychologists. The first is Steve Silberman, an American science journalist, who wrote the book Neurotribes:The Legacy of Autism and the Future of Neurodiversity (Silberman, 2015). Our second guide is Adam Feinstein, a journalist, Hispanist and father of Johnny who is autistic (Introducing myself | Adam Feinstein's blog," n.d.), author of A History of Autism: conversations with the pioneers (Feinstein, 2010). The lasts are two American journalists, John Donvan, multiple Emmy Award-winning, and Caren Zucker, mother of Mickey, diagnosed with autism, authors of the book In a different Key. The story of Autism (Donova\&Zucker, 2016). Although not academic books, the authors support their writing with rigorous citations to sources and impressing extensive documentation (Odom, 2016).

Each of the authors mentioned above was greatly acclaimed and received numerous prizes, but also their books reaped a whirlwind from some academics or part of the public. That is the reason why we were interested in having a scientific, hence impartial opinion on those three accounts of autism history. While researching for our project on ASD (Luştrea, A; Al Ghazi, L.; Borca, C., 2017), these books were brought to our attention by Simon BaronCohen who wrote: "a stunning big book NeuroTribes, big in size and big in vision, spanning the history of autism from the late 19th century to the present day" (Baron Cohen, 2015, p. 1329), "terrific book" (Baron Cohen, 2017, p. 746). About A History of Autism: conversations with the pioneers, Baron-Cohen said is "a treasure-trove" ("Praise for my new autism book | Adam Feinstein's blog," n.d.). The book In a different Key. The story of Autism is "a book whichmakes a remarkable contribution to the history of autism", in Baron-Cohen words ("A Definitive History of Autism - The Crown Publishing Group," n.d.). Baron-Cohen has his wellset place in the autism's history as the author of the book Theory of mind ( ), and as a multiawarded scientist. He is also professor of developmental psychopathology at University of Cambridge, and director of Autism Research Centre. After 40 years spent in the field of autism, if "Simon says" about a book that it is "one of the most fascinating accounts of autism I have ever read" and promise to "uncovers the secret that one scientist tried to hide" (Baron-Cohen, 2015, p. 1329), then that book is a must-read for anyone interested in autism. Silberman is taking us back in the $40 \mathrm{~s}$ and brings together both Kanner and Asperger in revealing "a well-kept secret about autism." 


\section{The West Side Story. Kanner}

The scientist who supposedly had secrets to hide would be Leo Kanner himself, not only the father of autism syndrom, but the father of child psychiatry in USA (Eisenberg's tribute to Kanner, cited by Feinstein, 2010)). Child psychiatrist at Johns Hopkins University School of Medicine in Baltimore, in 1943, he reported in his groundbreaking article that "since 1938 there have come to our attention some children whose condition differs so markedly and uniquely from anything reported so far" (Kanner, 1943, p. 217). Kanner described eleven cases of his child patients: they appeared isolated from the world, withdrawn from social contact, and most of them had severe intellectual difficulties (Kanner, 1943). He labeled these observed features as autistic. Actually, Kanner borrowed from Eugene Bleuler the term autism (from the Greek term autos = self), which means, literally, being absorbed in oneself, a morbid self-absorption (Evans, 2013) and credited the Swiss psychiatrist with introducing the term in psychiatry. Kanner repeatedly claimed that it was for the first time, in 1943, that such cases were described in the literature, so he was the first to name those features as autistic.

Silberman believes things are quite different and he also thinks he can prove it. As Baron-Cohen put it, "In science, as in commerce, or exploring space, being there first is important, and Silberman sees the real importance of what he has stumbled upon" (BaronCohen, 2015, p. 1329). What Silberman stumbled upon was the Hans Asperger's work and other authors publications that clearly shows Kanner descriptions of autistic traits were not the first ever reported, nor Kanner is the first to use the term autistic. However, Silberman was not the first to suggest that Kanner borrowed more than the term autism for his syndrome, but also the ideas of other psychiatrists. Adam Feinstein (2010) pointed on the same issues in his book, as well as Fitzgerald in the chapter "Autism: Asperger's Syndrome- History and First Descriptions"(Fitzgerald, 2008; Lyons \& Fitzgerald, 2007). Silberman however made a step forward by mentioning in premiere the link between Kanner and the Viennese scientists Georg Frankl.

Silberman made his case based on to the fact that before Frankl's arrival in the US, in Kanner's clinic, there is no evidence that Kanner had any interest in what we now call autistic behaviors (Robison, 2017). Frankl was the principal diagnostician in Asperger's 
Clinic in Vienna, where he worked for eleven years, five close to Asperger. As other jew colleagues before him and as well as his future wife, Anni Weiss, he ran from Nazi terror and left Vienna for the US. Silberman implies that through Frankl and his wife, Kanner saw the opportunity to make history in medicine describing a new condition, namely the autism, and never credited Asperger in his demarche. It is also Silberman's assumption that the Frankls remained silent feeling greatly in debt for Kanner facilitated their new life in the US. According to Kanner, his article presents "characteristics form of an unique syndrome, not heretofore reported" (Kanner, 1943, p. 242). Nevertheless, Frankl would have known that this was not the case, since he himself and his wife had presented similar descriptions as early as 1933-1935 (Donvan, Zucker, 2016; Robison, 2017; Silberman, 2015).

Anni Weiss-Frankl published in American Journal of Orthopsychiatry (Weiss, 1935) the case of Gottfried, a boy she consulted while she was working at the University Children's Clinic in Vienna. She left Vienna in 1934 and her future husband, Georg Frankl, in 1937. So, on 3 October 1938, when Asperger presented his thesis (Feinstein, 2010), in which he called his patients Autistischen Psychopathen, autistic psychopaths ${ }^{1}$ (Donvan \& Zucker, 2016), the Frankls were not in the auditorium. They were no longer in Europe, but in Kanner's inner circle at Johns Hopkins (Silberman, 2015). Silberman advanced the idea that if not from Anni Weiss, then Frankl surely must have heard the word autistic right from Asperger's lips, as a label for the children he consulted in his Clinic. Feinstein (2010, p. 11) citing Asperger's daughter, Maria Asperger Felder (2008), evokes a letter dated April 14, 1934, in which Asperger "discusses the difficulties of diagnostic concepts and suggests the possibility that autistic might be a useful term".

How close Frankl and Kanner's relation was, how much the two men talked about their cases, if Frankl really informed Kanner with details about his work with Asperger and how Asperger denominated the traits he observed in children, we do not know. Kanner only named Frankl as one of many clinicians whom he helped immigrate to America and credit him for conducting his observations and evaluations of two of his eleven cases, but never mentioned him in his work again (Silberman, 2015, citing Kanner's Unpublished memoirs).

\footnotetext{
${ }^{1}$ To note that in German, "psychopathy" has not the connotations of a profound mental illness as in English.
} 
However, if the two men have had talked about Asperger's work and vision, we can speculate it was not in 1938, but later. We say so because on 7 October 1938, four days after Asperger defended his thesis on autistic psychopaths in Vienna, Leo Kanner met five years old Donald Triplett for the first time in Baltimore.

After reading the detailed letter sent by Donald's father and meeting with the child, the most renowned child psychiatrist in the US was not able to provide a diagnostic to the parents. Instead, he sent little Donald to Frankl for further evaluation. After two weeks of tests and observations, Frankl notes "? Schizophrenia"(Silberman, 2015). Although the mother insisted for a diagnostic, Kanner had no label to give. "Donald was different from any other child he had treated and unlike any description in any textbook" (Donvan \& Zucker, 2016, p. 36). A year later, the diagnostic was still unclear. Kanner and Donald's mother wrote each other at least twice a month for the next four years. In 1942, the mother wrote again, reproaching that Kanner gave her only "generalities" whereas she needed "specifics" (Donvan \& Zucker, 2016). "Nobody realizes more than I do myself that at no time have you or your husband been given a clear-cut and unequivocal (...) diagnostic term"(Autism's First Child - The Atlantic, 2010). Finally, the name autistic for the disturbances Donald displayed is announced in a letter to Donald's mother on September 28, 1942, and became part of the title of his 1943 article (Donvan \& Zucker, 2016). A year later, Kanner comes with the name for the syndrome- early infantile autism (Kanner, 1944). However, the Frankls were not in Kanner's circle anymore. They left Baltimore at the end of 1940 (Silberman, 2015). So Kanner was on his own when he formulated his conception of the syndrome, between 1942 and 1944. How much the two-man talked about Frankl experience shared with Asperger, as a principal diagnostician in the Viennese Clinic, remains unknown.

Silberman produced however more circumstantial evidence than the others who accused, indirectly or directly, Kanner of plagiarism of ideas, by identifying Frankl as the connection between Kanner and Asperger. However, in Kanner's defense, we may say that his first case, the notorious Donald T., was referred to him in 1938 by the child's pediatrician and Donald fathers' letter stands for it. It is true that Frankl was involved in Donald's case (as well as in another one, Elaine's, who came an year later, in 1939), but it is also proved 
that in 1942 Kanner was still unsure how to label Donald's condition (see Kanner letter to Donald's mother). In a three year window (1938-1940), Frankl probably had many opportunities to talk to Kanner about the resemblances between his cases and Aspergers'. If Frankl did suggest the term autistic, taken from Asperger, why was Kanner hesitant in using it and waited until 1942 if he was eager to come first? If Kanner included aspects of Asperger's thinking into his own model of autism, without crediting him, still cannot be ruled out as a possibility.

If we admit that Kanner was not aware of Asperger work and that they applied the identical word to the independently observed behaviors, we can not agree with Kanner's claim that he was the first to describe those peculiar behaviors in children. Feinstein, citing Gilberg, inform us that Kanner was "so very well aware of people writing in other languages at the same time that Asperger was working" (Feinstein2010, p. 11). Even if he was not aware of Asperger's 1938 thesis, undoubtedly he was in current with the first account of "childhood schizophrenia" in America, published in 1933 by Howard Potter and also with Louise Despert several case histories reported in 1938 or in 1942 in a paper published in the same journal, Nervous child, in which Kanner published his seminal article in 1943 (Feinstein, 2010). Despert's reaction to the claims that the condition Kanner wrote about was "heretofore unreported" and "unique" was kind of "Had he not been reading my papers?“. Silberman is quoting Despert commenting Kanner: "It seems to me that the greatest contribution this article is making is in its thorough, accurate, and illuminating description of clinical cases," she wrote. "However, if you will permit me to say so, I object to the coining of new terminology for entities which, if not so carefully described, have been previously reported" (Silberman, 2015, p 124). She herself even referred to her cases with autism, but in Bleuler's sense of the term, as a clinical sign of schizophrenia. However, Kanner never considered autism as an early form or prodromal phase of schizophrenia, as Despert did, but as a condition sui generis. 


\section{The East Side Story. Asperger and Sukhareva}

Almost two decades before Kanner (1943) and Asperger (1944), Grunia Sukhareva described what we now call autistic traits in her original article, first published in Russian, in 1925, and next year, in German, under the title Die schizoiden Psychopathien im Kindesalter. For 2-years, she observed the children at Psychoneurological Department for Children in Moscow and then published six case reports of what she had called schizoid psychopathy in children, according to Bleuler and Kretschmer classification. Wolff translated in English Sukhareva's German version of the article (Wolff, 1996) and implies that Asperger must have been aware of Sukhareva's "structured, elegant and detailed descriptions" (Manouilenko \& Bejerot, 2015, p. 2). Wolf then raised the question: "How was it that Asperger...did not apparently know of this paper?" (Wolff, 1996, p. 120).

How much Asperger actually knew of Sukhareva's observations and her dilemma on the "disorder whose clinical picture shares certain features with schizophrenia, but which yet differs profoundly from schizophrenia" (Wolff, 1996, p. 131) it is hard to tell. Supposedly, at the University Clinic in Vienna, Frankl, Weiss or Asperger did not know about Sukhareva article, since none of them is citing her, although at the time there were not too many journals printed in German in the field of psychiatry. These journals were the first source of information for academics as well as for practitioners,so it is hard to believe that Asperger, who cited an article on child psychiatry published in the same journal, in 1938, never came across with his Russian colleague's paper. Sukhareva and Asperger both cited Bleuler and Kretschmer' s early work on schizoid personality in adults (Manouilenko \& Bejerot, 2015). However, none used the term autistic in relation to the cases described until Asperger gave the first public lectures on autism as early as 1938.

Asperger called his boys Autistischen Psychopathen. In German, the word psychopathy was akin "to the term personality disorder with none of the connotations of the deranged or criminal mind that it bore in English" (Donvan \& Zucker, 2016, p. 238). Asperger consciously has designated the word autistic to describe the inward, self-absorbed aspect that was reminiscent of schizophrenic withdrawal, but also unlike it. Schizophrenia is not present in young children, as early as the age of two and the children did not experience hallucinations or hear voices, as was typical of schizophrenia. The lack of social contact is 
present in schizophrenia and autism, like the fever is present in many conditions: as a symptom.

Asperger published The 'Autistic Psychopaths' in Childhood (in German, Die 'Autistischen Psychopathen' im Kindesalter) in Archiv fur Psychiatrie und Nervenkrankheiten, in 1944, an year after Kanner published Autistic disturbances of affective contact, in Nervous Child (Robison, 2017). Neither Asperger nor Kanner cited Suhkareva. The non-Germanspeaking researchers remained unfamiliar with the work of Asperger until 1981, when Wing presented the features of what she named Asperger Syndrome, and Uta Frith translated Asperger`s article, 47 years after his publication in German (Asperger, 1991).

\section{Rewriting the history of autism}

After bringing together Feinstein, Silberman and Donvan\&Zucker accounts an early history of autism, we concluded that Kanner's syndrome and "Kanner- father of autism" are myths demolished, in part, by the above mentioned. We limited ourselves to mention just the published articles of other authors prior to 1943-1944, to show that Kanner, in his own words "never discovered autism; it was always there" (Silberman, 2015, p. 188). Hundred years before 1943, there were records of what we now call autistic features and autistic people (see Donvan and Silberman's descriptions of Basil, the holy fool from Russia, Hugh Blair, Itard's wild boy of Aveyron, Howe's Case 27-Billy). If we can ignore those livresque accounts, we can not overlook the Suchareva, Weiss, Asperger and Despert reports, all the articles-published before 1943.

\section{Conclusions}

What we know:

1. Asperger was the first to use the word autistic to describe the unusual behaviors observed in children. He borrowed the term from the Bleuler's schizophrenia symptom list. In Bleuler's schizophrenic adult patients, the cutoff communication and the preference for isolation appeared to come and go, while Asperger observed that children do not withdraw and isolate, merely they "were never in". Although "extreme emotional isolation" from other people, which is "the foremost characteristic of early infantile autism", 
bears so close a resemblance to schizophrenic withdrawal (Feinstein, citing Kanner, p. 27), both Asperger and Kanner designated the term autistic being aware of these differences and explaining it repeatedly.

2. Sukhareva pointed out, two decades before Asperger, the distinction between the early-onset of the features observed in her children patients and the schizophrenic signs that appear later in adolescence and in young adults. In the last case, the patients almost invariably decline and disintegrate, while the children's condition often improves in time. Her merit is to accurately describe the traits such as the lack of interest and the lack of engagement in social contact, along with restricted and repetitive behaviors, and astutely observed that these differ from schizophrenia. Asperger concluded the same, but he came with the name autistic psychopathy instead of schizoid psychopathy for what later was labeled as Asperger syndrome.

3. Kanner was not the first to describe autistic traits, but he was the first to publish an article in which appeared both the differential diagnosis of the features he observed from childhood schizophrenia (as in Sukhareva and Asperger) and the label for them, autistic disturbances. He was the first to show that this complex set of behaviors constituted a single, never-before-recognized diagnosis: autism.

4. For years, Kanner maintained that his syndrome was monolithic by definition, limited to childhood. He also insisted that the autistic traits were innate, a hasty assumption since he never observed babies. Asperger, on the other hand, built his concept of autism as a broad and inclusive spectrum, a "continuum", as his diagnostician, Georg Frankl, called it in an unpublished draft from the '50s, cited by Silberman(2015). Wing, the architect of modern autism model as a spectrum, also noticed that.

Asperger and Kanner, although both labeled their cases autistic, they were focusing on different populations of children, and the conditions they described diverged in several important respects. The authors themselves insisted on the differences between them, until the very end: "Asperger, despite listing numerous similarities, considered his syndrome to be different from Kanner's" (Donvan \& Zucker, 2016, p. 241, citing Wing, 1981). Also, Kanner considered that Asperger "independently described what he called autistic psychopathy, which, if at all related to infantile autism, is at best a 42nd cousin" (Silberman, 
2015, p. 140, citing Kanner,1970). The spectrum model of autism set by APA in the 1980s represented a decisive defeat for the father of the this diagnosis and we will develop the suject in another paper.

What was implied but never proved:

Kanner appropriated the work of others.

In our opinion, there is no irrefutable evidence that Kanner was aware of Asperger's or Sukhareva's cases or that he appropriated or at least replicated their work in his Clinic, in Baltimore. We believe that Kanner could take the word autistic from Bleuler, as well as he could take it, via Frankl, from Asperger. Maybe he considered that in the worldwide psychiatric community the paternity of the term is so well-known, that in his first article he did not even mention Bleuler. He mentioned Bleuler years after, for introducing the word in psychiatry.

Kanner may have been unaware of Suckareva's and Asperger's preoccupation in children displaying what we now call autistic features, in an epoch in which access to European journals (or lectures) was not solely at a click distance. German-language papers were not very popular in the US, in the war-time, and remained unpopular many years later, as well as the German authors (if they were not jews or suspicions of Nazi collaboration planed upon them) as in Asperger's case (Donvan \& Zucker, 2016; Feinstein, 2010; Silberman, 2015). Although, Kanner may have been interested in German publications since he was a native speaker and the language barrier did not exist in his case. More than this, he was aware that psychiatry and psychopathology were born in Europe and the Americans have a lot to learn especially from German written literature in the field. It is our guess that if Kanner read German language psychiatry journals, it happened in US. At the time he was in Europe, he was not a psychiatrist so it is less probable that he was interested in the field (that is reading Suckareva's article).

Silberman's hypothesis that Frankl informed Kanner on his work with Asperger and Kanner took Asperger ideas and integrated into his own model of autism is not ungrounded, but was never fully proved. The same stands true for the allegations that Asperger knew about Sukhareva's cases in Moscow and all he did was to replicate her work in Vienna and stick the label autistic on it. 
Some questions still remain, but, without strong evidence, these are merely speculations. Our suspicions do not refer to the 40s, but to the 1970s events: why Kanner never cited Asperger? Even after that night in July 1969, when he stated that "I never discovered autism. It was there before", he maintained the view that somehow Asperger's work was unworthy of serious consideration. Why did Asperger not say more on Kanner's work? Why they never met, why they never wrote to each other? Was the scientist's pride, was it that "jewish-german thing"? The only person in the world to answer those questions could have been Georg Frankl. But he decided to remain silent. Like Gottfried in Annie's 1935 article, Frankl's case, Karl, was not described as autistic, although he met all the criteria to be portrayed in this way, due to his "lack of contact with persons in its most extreme form" (Silberman citing Frankl, 1943). Frankl knew from Asperger that autistic term would be best suited to describe Karl K. He preferred not to. Why? Maybe because his article appeared in the same year and in the same journal in which Kanner published. And, by doing that, he would somehow contradict his former boss and benefactor's theory?

Silberman (2015) was talking about Kanner's sin of omission. Echoing Silberman, we would rather point on Frankl's sin of omission and conclude with Silberman's words: "And the one clinician in America who knew the real story was not apt to say anything about it in public, because he owed Kanner the ultimate debt: his life" (Silberman, 2015).

\section{Acknowledgments:}

The author expresses sincere gratitude to Anca Luștrea, a dearest colleague, for her kind comments that significantly improved the manuscript, for her unconditional day-andnight support and her constant encouragements.

\section{References:}

American Psychiatric Association (APA). (1980).Diagnostic and Statistical Manual of Mental Disorders, 3rd ed. Washington, DC:American Psychiatric Publishing.

American Psychiatric Association (APA). (1994). Diagnostic and Statistical Manual of Mental Disorders (4th ed.). Washington, DC: American Psychiatric Publishing.

A Definitive History of Autism - The Crown Publishing Group. (n.d.). Retrieved December 14, 2018, from http://crownpublishing.com/archives/feature/23418\#.XBNshmgzZPY

Asperger, H. (1991). 'Autistic psychopathy' in childhood. In U. Frith (Ed.), Autism and Asperger 
syndrome (pp. 37-92). Cambridge: Cambridge University Press. https://doi.org/10.1017/CB09780511526770.002

autism | Origin and meaning of autism by Online Etymology Dictionary. (n.d.). Retrieved December 8, 2018, from https://www.etymonline.com/word/autism

Baron-Cohen, S. (2015). Leo Kanner, Hans Asperger, and the discovery of autism. The Lancet. https://doi.org/10.1016/S0140-6736(15)00337-2

Baron-Cohen, S. (2017). Editorial Perspective: Neurodiversity - a revolutionary concept for autism and psychiatry. Journal of Child Psychology and Psychiatry, 58(6), 744-747. https://doi.org/10.1111/jcpp.12703

Donvan, J.; Zucker, C. (2010). Autism's First Child. The Atlantic. Retrieved from https://www.theatlantic.com/magazine/archive/2010/10/autisms-first-child/308227/

Donvan, J.; Zucker, C. (2016). In a different key : the story of autism. New York: Crown Publishers.

Evans, B. (2013). How autism became autism: The radical transformation of a central concept of child development in Britain. History of the Human Sciences, 26(3), 3-31. https://doi.org/10.1177/0952695113484320

Feinstein, A. (2010). A History of Autism: Conversations with the Pioneers (1 edition). WileyBlackwell. https://doi.org/10.1002/9781444325461

Fitzgerald, M. (2008). Asperger's disorder. In J. L. Rausch, M. E. Johnson, \& M. F. Casanova (Eds.), Asperger's disorder (p. 369). Informa Healthcare.

In a Different Key. (n.d.). Retrieved December 12, 2018, from http://www.inadifferentkey.com/author-qa

Introducing myself | Adam Feinstein's blog. (n.d.). Retrieved December 12, 2018, from https://adamfeinstein.wordpress.com/about/

Kanner, L. (1943). Autistic disturbances of affective contact. Nervous Child, 2, 217-250. Retrieved from http://www.neurodiversity.com/library_kanner_1943.pdf

Kanner, L. (1944). Early infantile autism. The Journal of Pediatrics, 25(3), 211-217. https://doi.org/10.1016/S0022-3476(44)80156-1

Luştrea, A., Al Ghazi, L., \& Borca, C. (2017). Innovative Academic Course on Integrative Interventions for Children with Autism Spectrum Disorders. Journal of Educational Sciences, 2(36), 56-68. Retrieved from https://www.eu-aims.eu/autism-spectrum-disorder-asd/

Lyons, V., \& Fitzgerald, M. (2007). Asperger (1906-1980) and Kanner (1894-1981), the two pioneers of autism [2]. Journal of Autism and Developmental Disorders. https://doi.org/10.1007/s10803007-0383-3

Manouilenko, I., \& Bejerot, S. (2015). Sukhareva-Prior to Asperger and Kanner. Nordic Journal of Psychiatry, 69(6), 1761-1764.

https://doi.org/10.3109/08039488.2015.1005022

Odom, S. L. (2016). Steve Silberman: NeuroTribes: The Legacy of Autism and the Future of Neurodiversity. Journal of Autism and Developmental Disorders, 46(5), 1885-1886. https://doi.org/10.1007/s10803-016-2726-4

Praise for my new autism book | Adam Feinstein's blog. (n.d.). Retrieved December 10, 2018, from https://adamfeinstein.wordpress.com/2010/07/05/praise-for-my-new-autism-book/

Robison, J. E. (2017). Kanner, Asperger, and Frankl: A third man at the genesis of the autism 
diagnosis. Autism, 21(7), 862-871. https://doi.org/10.1177/1362361316654283

Silberman, S. (2015). Neurotribes : the legacy of autism and the future of neurodiversity (Reprint ed). New York: Avery.

Simon Baron-Cohen - Autism Research Centre. (n.d.). Retrieved December 9, 2018, from https://www.autismresearchcentre.com/people_baron-cohen

Simon Baron-Cohen -Google Academic. (n.d.). Retrieved December 9, 2018, from https://scholar.google.ro/citations?user=4GAQ-RUAAAAJ\&hl=ro\&oi=ao

Steve Silberman. (n.d.). Retrieved December 14, 2018, from http://stevesilberman.com/

Weiss, A. B. (1935). Qualitative intelligence testing as a means of diagnosls in the examination of psychopathic children. American Journal of Orthopsychiatry, 5(2), 154-179. https://doi.org/10.1111/j.1939-0025.1935.tb06338.x

Wing, L. (1981). Asperger's syndrome: a clinical account. Psychological Medicine, 11(01), 115. https://doi.org/10.1017/S0033291700053332

Wolff, S. (1996). The first account of the syndrome Asperger described? European Child \& Adolescent Psychiatry, 5(3), 119-132. https://doi.org/10.1007/BF00571671 